\title{
Editorial:
}

\section{Transportador de yodo (NIS) y su aplicación diagnóstica y terapéutica en diferentes enfermedades \\ GARCILASO RIESCO-EIZAGUIRRE; PILAR SANTISTEBAN}

Durante más de 60 años, la capacidad única de la glándula tiroidea de transportar y acumular yodo ha sido la base del diagnóstico y el tratamiento con yodo radiactivo del hipertiroidismo y del cáncer diferenciado de tiroides y sus metástasis. Sin embargo, se conocía muy poco de sus bases moleculares. A partir de la caracterización molecular en 1996 de la proteína transportadora de yodo NIS (del inglés, Na/l symporter), se ha abierto un nuevo campo de investigación muy interesante y productivo, con multitud de estudios básicos y clínicos publicados. El gran interés generado por NIS no sólo es debido a sus peculiaridades electrocinéticas como transportador de yodo y otros iones, ni a la contribución que ha supuesto para nuestro entendimiento de la fisiopatología tiroidea, sino sobre todo por la repercusión que su estudio puede tener en la clínica. NIS ha abierto el camino para nuevas estrategias terapéuticas en el cáncer de tiroides y de mama, y ha demostrado ser un excelente candidato para la terapia génica. En este editorial comentaremos los avances más importantes en la investigación sobre este transportador.

NIS tiene un papel crucial en la fisiología de la célula tiroidea, ya que es el primer paso en la síntesis de las hormonas tiroideas. NIS transporta yodo junto con 2 átomos de sodio de forma activa al interior de la célula por la membrana basolateral y, una vez en su interior, el yodo pasa por la membrana apical al coloide, gracias a transportadores como la pendrina y otros que aún no se conocen. La enzima tiroperoxidasa (TPO), situada en la membrana apical, actúa sobre el yodo mediante una reacción compleja en 3 pasos secuenciales:

primero lo oxida, segundo lo incorpora a los residuos de tirosina de la tiroglobulina (Tg) y tercero cataliza el acoplamiento de 2 residuos de tirosina yodados que formarán las futuras hormonas tiroideas. Este proceso es denominado organificación del yodo y es inhibido por compuestos como el propiltiouracilo (PTU) y el metimazol (MMI) que inhiben la actividad de TPO. Dependiendo de las necesidades de hormonas tiroideas por parte del organismo, la $\mathrm{Tg}$ yodada es endocitada por la membrana apical en forma de gotas de coloide que posteriormente son degradadas por las enzimas lisosomales, liberándose T3 y T4 al torrente sanguíneo. Todo este proceso está regulado por la hormona estimuladora del tiroides (TSH), que tras su unión a su receptor (TSHR), localizado en la membrana basolateral, activa las vías dependientes del AMPc e induce el transporte de yodo por regulación de la expresión de NIS tanto transcripcional como postranscripcional.

\section{NIS EN LAS ENFERMEDADES TIROIDEAS BENIGNAS}

El hipotiroidismo congénito aparece en 1 de cada 3.000 neonatos $y$, si no se trata correctamente, puede producir defectos irreversibles en el sistema nervioso. Los defectos en el transporte de yodo (ITD OMIM 274400) son causa de hipotiroidismo congénito autosómico recesivo y se deben a mutaciones en el gen NIS. Se han identificado 11 mutaciones en humanos y todos guardan un perfil clínico similar: hipotiroidismo en grado variable, bocio, ausencia de captación de yodo y un ratio saliva/plasma de yodo bajo. El estudio funcional de estas mutaciones es importante porque nos enseña cuáles son los mecanismos mediante los que NIS transporta yodo. Por ejemplo, una de las mutaciones 
descritas impide la localización de NIS en membrana y hace que se exprese en citoplasma; éste es el motivo por el cual no es funcional. Como veremos más adelante, esto tiene mucho interés porque el mecanismo por el cual NIS se localiza en membrana está alterado en cáncer de tiroides. El papel de NIS como un autoantígeno en la enfermedad tiroidea autoinmunitaria ha sido ampliamente estudiado y hay evidencias de que algunos pacientes expresan anticuerpos dirigidos contra NIS en el suero. Sin embargo, el efecto biológico de estos autoanticuerpos no está claro y de momento la utilidad de su determinación en la clínica es controvertida.

\section{NIS Y CÁNCER DE TIROIDES}

Es bien sabido que la captación de yodo está disminuida en el cáncer de tiroides comparado con el tejido tiroideo normal y por eso se diagnostican como nódulos fríos en la gammagrafía. Para estimular la captación de yodo en las células tumorales, en clínica se elimina la medicación supresora para elevar la TSH endógena o se administra directamente TSH recombinante humana, lo cual indica que estas células todavía conservan cierto grado de diferenciación y de respuesta hormonal. En algunos casos, el cáncer de tiroides pierde por completo la capacidad de captar yodo y el pronóstico empeora considerablemente. Tras la caracterización de NIS, se pensó que su expresión faltaría o estaría muy disminuida en el cáncer de tiroides. Sin embargo, varios estudios demostraron que hasta un $70-80 \%$ de los cánceres de tiroides expresaban valores normales e incluso aumentados de NIS. También se observó que NIS estaba retenido en el citoplasma y no en la membrana basolateral. Esta localización del transportador en la membrana es necesaria para que sea funcional y capte el yodo. Esto pone de relieve que no basta con que NIS se exprese, sino que lo debe hacer en la membrana celular para que sea plenamente funcional y, por tanto, cualquier estrategia para volver a expresar NIS en la célula tiroidea necesita tener en cuenta ese hecho.

Como el cáncer de tiroides conserva cierto grado de diferenciación, una estrategia lógica es conseguir diferenciar de nuevo la célula tumoral para que NIS se exprese de una forma funcional y poder aumentar la sensibilidad al tratamiento con yodo radiactivo. Uno de los primeros y más estudiados compuestos basados en esta estrategia, y que se ha usado incluso antes de la caracterización de NIS, ha sido el ácido retinoico (RA). Es bien conocido que este derivado de la vitamina A tiene un papel en la diferenciación y la proliferación celular y actúa a través de sus receptores nucleares RAR y RXR. RAR tiene 3 isoformas (, _ y _) que tienen un patrón de distribución específico en los tejidos. El ligando all trans $R A$ (tRA) es un "pan retinoide" no selectivo que se une a todas las isoformas. Hay múltiples estudios clínicos que han utilizado tRA en el cáncer de tiroides metastásico que no capta

yodo con resultados dispares y series difícilmente comparables entre sí3. En términos generales, la captación de yodo radiactivo aumentó en el $20-42 \%$ de los casos, si bien la eficacia en reducir masa tumoral fue mucho menos; no sobrepasa el $16 \%$ en la serie con mayor número de casos publicada hasta la fecha. Actualmente se están investigando los nuevos agonistas RAR selectivos de isoforma, en concreto los selectivos de RAR_/ y parecen ser más eficaces y tener menos toxicidad que los no selectivos.

La caracterización molecular de NIS ha propiciado nuevas estrategias basadas en los mecanismos moleculares que regulan su expresión génica y ha dado pie a una serie de estudios in vitro con resultados interesantes que han de ser confirmados in vivo. La desacetilación de histonas es un mecanismo de silenciamiento de la transcripción génica y 
su regulación parece estar alterada en el cáncer. Las histonas son 4 proteínas que forman un octámero alrededor del cual se enrolla el ADN formando los nucleosomas y su estado de acetilación regula en parte la expresión génica. Agentes inhibidores de las desacetilasas de histonas como el depsipéptido (FR901228), la tricostatina A (TSA) y el ácido valproico parecen reinducir la expresión de NIS funcional en algunas líneas tumorales de tiroides. Otra de las estrategias se basa en el hecho de que el promotor de NIS está metilado tanto en tumores benignos como malignos de tiroides, así como en diversas líneas celulares de cáncer de tiroides. La metilación es un mecanismo utilizado por la célula para silenciar genes y se sabe que durante el proceso de transformación tumoral hay una metilación aberrante. Es bien sabido que ciertos agentes desmetilantes tienen un efecto terapéutico en algunos tipos de cánceres. La 5-azacitidina es un agente desmetilante que ha sido capaz de restaurar la captación de yodo en algunas líneas celulares de cáncer de tiroides. Por último, los agonistas de PPAR_, entre otros efectos, producen inhibición de la proliferación e inducción de apoptosis. Aunque su papel en la carcinogénesis está aún por dilucidar, la troglitazona parece no sólo inhibir la proliferación e inducir apoptosis, sino que también incrementa los valores de ARNm de NIS en varias líneas celulares. Es evidente que se necesitan estudios in vivo que avalen el empleo de estos nuevos compuestos que parecen diferenciar de nuevo la célula tumoral tiroidea in vitro y que muy probablemente la combinación de estas estrategias mejore el efecto terapéutico en el paciente con una toxicidad menor.

La expresión de NIS en el cáncer de tiroides ha sido objeto de varios estudios para dilucidar su papel como un potencial marcador pronóstico. En un estudio retrospectivo se encontró que la presencia de NIS por inmunohistoquímica $(\mathrm{IH})$ en los tumores primarios se correlacionaba con la captación positiva de yodo radiactivo en las subsiguientes metástasis. Sin embargo, este estudio no tuvo en cuenta si NIS se localizaba o no en la membrana y la ausencia de NIS en el tumor primario no predijo recurrencias negativas en el rastreo con yodo radiactivo. Otro estudio observó que una expresión baja de NIS en el tumor primario, medida por RT-PCR, se correlacionaba con tumores más agresivos. Por último, nuestro estudio demuestra que los carcinomas papilares BRAF positivos (los cuales son más agresivos y se asocian a recurrencias que no captan yodo) se correlacionan con una baja expresión de NIS en la membrana. NIS puede convertirse en el futuro en un marcador pronóstico en el cáncer de tiroides, aunque se necesitan más estudios.

\section{NIS Y CÁNCER DE MAMA}

La acumulación de yodo en la mama lactante fue descrita hace más de 40 años. El yodo acumulado en la leche materna es utilizado por el recién nacido para la biosíntesis de las hormonas tiroideas. Una forma especializada de NIS, menos glucosilada que la tiroidea, media el transporte activo del yodo en el tejido mamario, y está presente en la membrana basolateral de las células epiteliales alveolares y en pequeñas células epiteliales ductales. A diferencia de lo que ocurre en la glándula tiroidea, donde la expresión de NIS es constitutiva, la glándula mamaria no lactante no expresa NIS y sólo está presente en el final de la gestación y durante la lactancia. Además, las hormonas prolactina, oxitocina y estrógenos son las principales reguladoras de su expresión y función. Especialmente interesante ha sido el hallazgo de NIS en estados patológicos de la glándula mamaria, en concreto en el cáncer de mama. Ratones transgénicos que expresan las formas activas de los oncogenes Ras o Neu en el tejido mamario generan adenocarcinomas de mama que 
sorprendentemente expresan NIS y acumulan yodo radiactivo in vivo. En humanos, se ha demostrado que un porcentaje muy alto de los carcinomas ductales in situ e invasivos (80$90 \%$ ) expresan NIS, frente al tejido peritumoral y muestras de tejido mamario normal que no lo expresan6. Además, Moon et al estudiaron la captación de 99mTc04 (isótopo radiactivo captado también por NIS, pero con una vida media menor) en 25 pacientes con carcinoma de mama y observaron captación en 4, que además se correlacionó con la expresión de NIS en el tejido. En otro estudio, 27 mujeres con cáncer metastásico de mama fueron sometidas a estudios de gammagrafía con 99mTc04 o 123l. Antes se les había suprimido la función tiroidea con T3 y con posterioridad se estudió NIS por IH en los tumores primarios y metastásicos. Se observó captación en el $25 \%$ de los casos de los tumores que expresaban NIS. Los autores calcularon por dosimetría la posibilidad de administrar dosis ablativas con yodo radiactivo de las metástasis y propusieron que la supresión de la función tiroidea con T3 hacía factible la ablación radiactiva de las metástasis sin dañar el tiroides. Hacen falta más estudios que confirmen estos resultados en condiciones óptimas, pero de confirmarse abriría la posibilidad de una nueva herramienta de diagnóstico por imagen para estos tumores y, quién sabe, una nueva herramienta terapéutica. Además, al igual que en el cáncer de tiroides, se está investigando terapias para volver a inducir diferenciación en la célula tumoral mamaria in vitro, con el objeto de aumentar la expresión de NIS. En concreto, se ha experimentado con agonistas del RA selectivos de isoforma (RAR___) en combinación con agonistas del RXR (9-cis RA), y se obtuvo mejores resultados y menos toxicidad que con los agonistas no selectivos (tRA). También la combinación de los agonistas RAR_/_ con dexametasona ha dado buenos resultados.

\section{NIS Y TERAPIA GÉNICA}

Dada la gran eficacia y los pocos efectos secundarios del tratamiento con yodo radiactivo en el cáncer diferenciado de tiroides, sería deseable poder aplicar este tratamiento a otros cánceres. Esto es posible gracias a la terapia génica, es decir, la transferencia mediante un vector viral de un gen ectópico al tejido tumoral para que, de forma directa o indirecta, induzca destrucción tumoral. NIS sería un excelente gen candidato para terapia génica porque tendría la virtud única de poder ser utilizado con fines diagnósticos y terapéuticos.

Es decir, se podría monitorizar la eficacia de la transferencia del vector viral al tejido tumoral mediante estudios de captación con yodo radiactivo y luego tratar con dosis ablativas para buscar un efecto terapéutico. Por tanto, NIS podría tener un doble efecto como gen diagnóstico y como gen usado en terapia y son múltiples los estudios tanto in vitro como in vivo que así lo avalan. Aunque el camino que hay que recorrer para aplicar la terapia génica en humanos todavía es grande, debido al problema no resuelto de la toxicidad viral en tejidos no tumorales, hay múltiples estudios in vivo muy prometedores en el uso de este transportador. La utilización de promotores específicos de tejido ha supuesto un avance en terapia génica, ya que permite una expresión selectiva del gen en la célula maligna, minimizando los efectos secundarios en las células no malignas. Se han generado construcciones virales con NIS bajo el control del promotor del antígeno prostático (PSA) específico para el tratamiento con yodo radiactivo del cáncer de próstata, el promotor mínimo de inmunoglobulinas para el mieloma, el promotor del antígeno carcinoembrionario (CEA) para el cáncer de colon, el promotor de la calcitonina para el carcinoma medular de tiroides y recientemente se está utilizando promotores de genes asociados a malignidad pero que se expresan en varios tipos de tumores malignos, como es el caso de MUC1 
(mama, páncreas y ovario) y el promotor de la telomerasa que estamos estudiando actualmente en nuestro laboratorio. Otra de las ventajas de NIS como gen múltiples radioisótopos. No sólo los derivados del yodo, como 125I, 124I o 123I, o con un perfil similar, como el tecnecio (99mTc04), ya conocidos, sino también otros todavía en estudio capaces de ser transportados por NIS de una manera específica y con propiedades físicas superiores al yodo radiactivo, como es el caso del renio (118Re) o la astato (211 At). Especialmente prometedor es el renio, un potente betaemisor derivado del tecnecio, con una vida media de $16 \mathrm{~h}$ y un rango de acción mayor que el $131 \mathrm{l}$ (hasta $32 \mathrm{~mm}$ ), lo cual lo hace a priori más eficaz en caso de tumores grandes. Hay 2 estudios en líneas celulares de hepatocarcinoma y de glioma en los que se demuestra un efecto terapéutico del renio muy interesante.

En conclusión, la investigación sobre NIS se extiende desde su caracterización molecular y el estudio de su regulación en la célula tiroidea hasta su aplicación en el tratamiento del cáncer, ya sea con estrategias para volver a diferenciar el tejido tumoral (como en el caso del cáncer de tiroides o el de mama) o como gen candidato para la terapia génica de otro tipo de cánceres. NIS ha resultado ser una molécula muy versátil que ha abierto un amplio y atractivo campo de investigación traslacional. 